\title{
Saved by sequestration?
}

\author{
Carbon capture and storage could be the only way of managing atmospheric carbon dioxide levels \\ responsibly. But it is by no means clear that it will work.
}

It is time for a fresh approach to climate change. Asking nations to reduce their greenhouse-gas emissions is apparently asking too much: there is no sign of a downturn in global $\mathrm{CO}_{2}$ emissions. Confidence in the ability of the world's leaders to forge a new, legally binding climate treaty in Copenhagen this month is dwindling. And even if an agreement is reached next year, it seems unlikely that self-imposed restrictions will suffice to keep the climate stable in the long run.

Zero emissions of $\mathrm{CO}_{2}$ are the only way of stabilizing climate. This underappreciated fact has come into sharp focus since the publication of the insight that cumulative $\mathrm{CO}_{2}$ emissions determine the long-term climate outcome, essentially independent of the evolution of $\mathrm{CO}_{2}$ releases over time (Nature 458, 1158-1166; 2009). But judging from past developments, zero global emissions look unachievable, at least in the next few decades: so far, we haven't even been able to stop rates of $\mathrm{CO}_{2}$ emissions from continuing to increase. In this situation, carbon capture and storage - the idea of stripping $\mathrm{CO}_{2}$ from exhaust fumes before they enter the atmosphere, and storing the gas in a safe place - could be the only solution.

Carbon capture and storage has entered mainstream thinking in the past few years. Yet the technology is not tested and established at any useful scale. In this focus issue, we have collected opinion pieces that argue for an open discourse on the options for carbon sequestration: all the ways of reducing atmospheric $\mathrm{CO}_{2}$ concentrations need to be re-examined, weighed up against each other and, importantly, against expected damages from unabated emissions. For example, much of the environmental impact of generating fuel from coal could conceivably be circumvented (see Commentary on page 818 ), and damages from deep-ocean disposal of $\mathrm{CO}_{2}$ (see Commentary on page 820) may, at some point in the future, pale in comparison with the effect of high atmospheric $\mathrm{CO}_{2}$ levels.

In addition, in this issue we present three Progress Articles that review the state of the science regarding sources and sinks of $\mathrm{CO}_{2}$ and other greenhouse gases, and our current understanding of the safest option

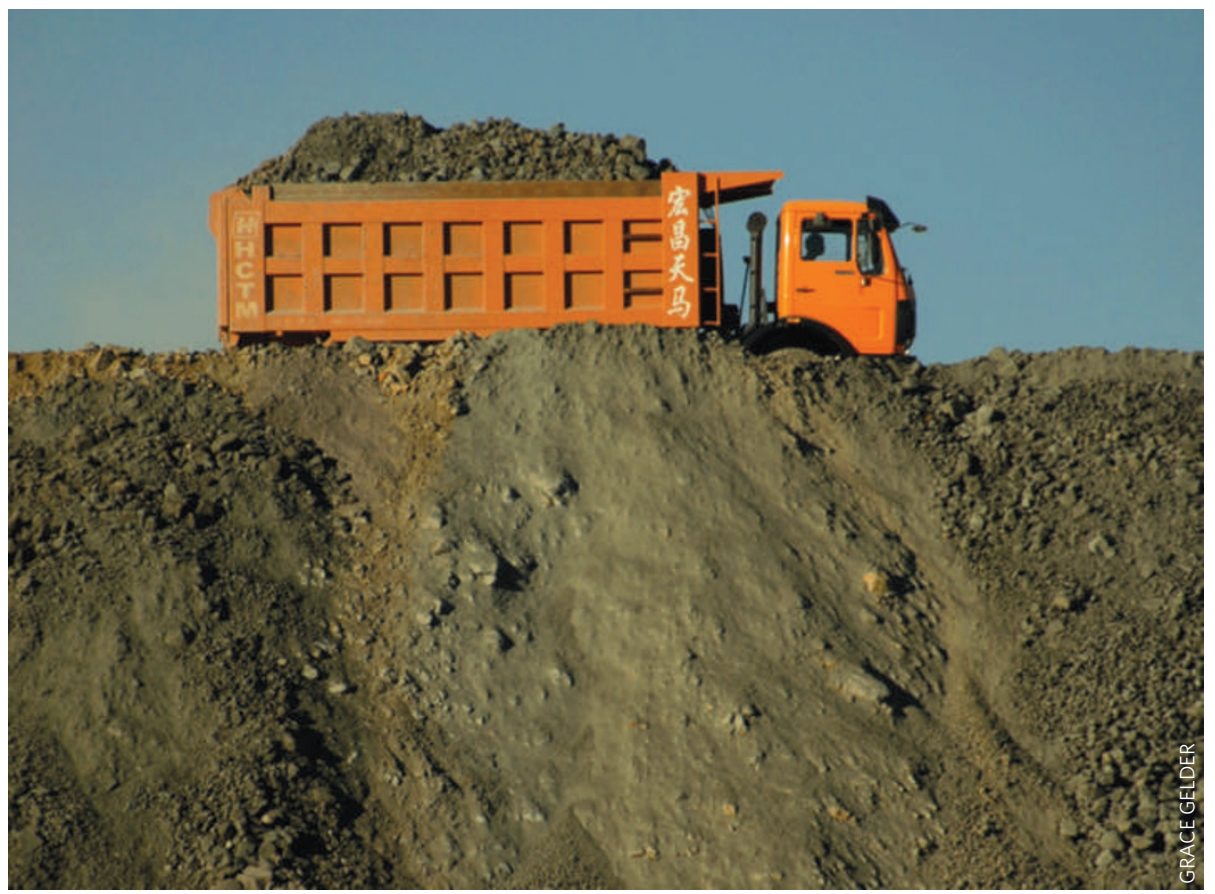

Coal production. If we continue to burn fossil fuels, we will need to find ways of burying the resulting carbon dioxide.

for sequestration - mineral carbonation. In this process, chemical reactions are induced between fluid or gaseous $\mathrm{CO}_{2}$ and surrounding rocks, leading to the formation of stable carbonate minerals.

The emerging picture is one of urgency: the Earth's carbon sinks, which have faithfully taken up the majority of anthropogenic $\mathrm{CO}_{2}$ emissions since the industrial revolution, may already be in decline (see page 826 and Progress Article on page 831 ), although there are also indications to the contrary (Geophys. Res. Lett. 36, L21710; 2009). And mineral carbonation needs substantial further research before its capacity can be estimated (see Progress Article on page 837). Moreover, the problem does not necessarily end with carbon sequestration. At least for Europe and for the years 2000 to 2005 , methane and nitrous oxide emissions negated carbon uptake in forests and grasslands (see Progress Article on page 842 ). Controlling emissions of other greenhouse gases will need attention, too.

We do not know at what level atmospheric $\mathrm{CO}_{2}$ concentrations become a severe danger to life or property, or which of the projected dangerous changes will hit first. Nor can we be sure of the total amount of $\mathrm{CO}_{2}$ emissions that will lead to any predetermined level of $\mathrm{CO}_{2}$, given that natural carbon sinks are variable. It would therefore be wise to make every effort to investigate technologies that give us the option of stripping $\mathrm{CO}_{2}$ from the atmosphere after it has been emitted: air capture, for example, would allow us to revert back to lower atmospheric $\mathrm{CO}_{2}$ levels, should we overshoot (see Correspondences on page 811 ).

But first and foremost, carbon capture and storage needs a concerted scientific effort. Capacities for geological storage are uncertain, pilot projects for deepocean sequestration have been halted, and public acceptance of both options is at best questionable - not least because full risk assessments based on solid scientific data are scarce. These questions need to be addressed sooner rather than later, if carbon sequestration is to become the solution for the climate problem. 